SILVA, V.L. et al. Caracterização físico-química e bioquímica do farelo de palma forrageira redonda (Opuntia ficus) utilizado na alimentação de ruminantes. PUBVET, Londrina, V. 5, N. 2, Ed. 149, Art. 1002, 2011.

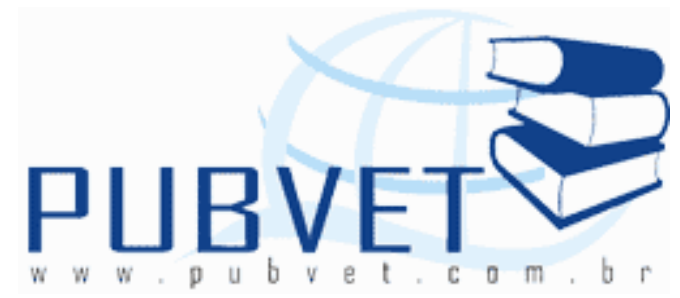

PUBVET, Publicações em Medicina Veterinária e Zootecnia.

\title{
Caracterização físico-química e bioquímica do farelo de palma forrageira redonda (Opuntia ficus) utilizado na alimentação de ruminantes
}

\author{
Vinícius Lopes da Silva ${ }^{1}$, Lívia Santos Costa $^{1}$, Milena Patricia Viana Bastos ${ }^{1}$, \\ Lívia Maria Araújo Macedo Facuri², Newton Oliveira Rêgo Júnior ${ }^{3}$, Marcondes \\ Viana da Silva ${ }^{4}$
}

${ }^{1}$ Zootecnista e mestrando (a) do PPGZ/UESB. Bolsista do CNPq/CAPES;

${ }^{2}$ Zootecnista, professora do IFBaiano e doutoranda do PPGZ/UESB;

${ }^{3}$ Graduando em Engenharia de Alimentos/UESB;

${ }^{4}$ Farmacêutico-Bioquímico, D.Sc. e Professor Titular do DEBI-PPGZ/UESB.

\section{Resumo}

Objetivou-se com essa pesquisa determinar a característica físico-química e bioquímica do farelo de palma forrageira redonda (Opuntia fícus), utilizado na alimentação de ruminantes. As amostras de palma redonda foram coletadas, a nível de campo, na cidade de Jequié-Ba. Estas foram cortadas, desidratadas e moídas para análise. A palma apresentou baixos teores de matéria seca, proteína bruta, fibra em detergente neutro e fibra em detergente ácido, já os carboidratos não fibrosos tiveram valores expressivos, considerado importante fonte de energia. As determinações dos teores de compostos fenólicos totais e taninos condensados foram efetuadas em triplicata. Os resultados foram apresentados 
SILVA, V.L. et al. Caracterização físico-química e bioquímica do farelo de palma forrageira redonda (Opuntia ficus) utilizado na alimentação de ruminantes. PUBVET, Londrina, V. 5, N. 2, Ed. 149, Art. 1002, 2011.

como a média \pm desvio padrão (DP) e foram calculados usando o software Excel. Observou-se baixos teores de fenólicos totais e taninos condensados na espécie, a qual apresentou uma média de 168 e $119,71 \mathrm{mg} / 100 \mathrm{~g}^{-1}$ de catequina, ou 0,17 e 0,12 quando expressos em \% da matéria seca. Evidenciou-se uma quantidade insignificante desses compostos bioativos não causando efeitos adversos nos animais alimentados com palma.

Palavras-chave: alimentação, caracterização, fatores antinutricionais, vanilina

\title{
Forrage palm round meal (Opuntia ficus) chemistry physical and biochemical characterization, fed to ruminants
}

\begin{abstract}
The aim of this research was to determine the characteristic chemistry physical and biochemistry characteristics of the forrage palm round (Opuntia ficus) meal, fed to ruminants. Forrage palm samples were collected, at field level, in Jequié city - BA. It was cut, dried and grounded for analysis. Forrage palm meal has shown low dry matter, crude protein, neutral detergent fiber and acid detergent fiber, since the non-fibrous carbohydrates, which are considered important source of energy, had significant values. Determinations of total phenolics and condensed tannins levels were performed in triplicate. Results were presented as mean \pm standard deviation (SD) and were calculated by Excel software. Low levels of total phenolics and condensed tannins were observed in this species, which has shown an average of 168 and $119.71 \mathrm{mg} / 100 \mathrm{~g}-1$ of catechin, or 0,17 and 0,12 when expressed as \% of dry matter. Insignificant amount of these bioactive compounds were observed, causing no adverse effects in animals.
\end{abstract}

Keywords: feed, characterization, antinutritional factors, vanillin 
SILVA, V.L. et al. Caracterização físico-química e bioquímica do farelo de palma forrageira redonda (Opuntia ficus) utilizado na alimentação de ruminantes. PUBVET, Londrina, V. 5, N. 2, Ed. 149, Art. 1002, 2011.

\section{Introdução}

A estacionalidade da produção de forragem em zonas áridas e semi-árida é provocada pela distribuição irregular das chuvas associada a um manejo de pastagem deficiente, é uma realidade que se repete todos os anos no Nordeste brasileiro e em ouras regiões. De acordo com Nozella (2001), durante o período de escassez de alimentos, pequenos e grandes ruminantes consomem folhas de árvores e arbustos que caem no solo. Essas folhas são de baixo valor nutritivo e não atendem às necessidades nutricionais dos animais. Isto reflete a baixa produtividade na exploração de ruminantes, causando fortes transtornos econômicos, gerando aflição e apreensão para os pecuaristas, além de causar sérios problemas sociais. Segundo Silva et al. (2006), desta forma, torna-se necessário a busca de alimentos alternativos para os ruminantes, no período de baixa disponibilidade de forragem.

As forrageiras nativas das regiões áridas e semi-áridas vêm sendo alvo de pesquisas, em busca de alimentos com alto valor nutritivo para os animais criados nesses locais, dentre elas destaca-se a palma forrageira redonda (Opuntia fícus), uma fonte energética de baixo custo e disponível na região (Melo et al., 2003), mas esta, pode apresentar alguns empecilhos para a alimentação de ruminantes, como os altos níveis de fatores antinutricionais, tendo como principal exemplo os taninos.

Nozella (2001) relata que o conteúdo de taninos nas plantas pode variar de acordo com as condições climáticas e geográficas. Os taninos apresentam uma composição química variada, sendo, muitas vezes, pouco conhecida. O efeito desses compostos inclui a inibição da fermentação no rúmen, pela ligação a proteínas e fibras, tornando-as resistentes à digestão, ou indiretamente, pela ligação com enzimas digestivas, prevenindo sua ação catalítica. Vários são os métodos utilizados para a análise de fenóis totais e taninos totais, entretanto 
SILVA, V.L. et al. Caracterização físico-química e bioquímica do farelo de palma forrageira redonda (Opuntia ficus) utilizado na alimentação de ruminantes. PUBVET, Londrina, V. 5, N. 2, Ed. 149, Art. 1002, 2011.

devido a essa variação na estrutura e composição torna-se difícil adequar os resultados analíticos aos efeitos nos animais.

Os métodos tradicionais de análise de alimentos não incluem medidas quantitativas dos taninos e, em razão disso, pouco se sabe a respeito da natureza desses compostos nas espécies tropicais, em especial nas nativas do Nordeste brasileiro (Beelen, 2002). Taninos são compostos fenólicos solúveis em água, com alto peso molecular, que contêm grupos hidroxila fenólica, capazes de complexar e precipitar proteínas em soluções aquosas (Silva \& Silva, 1999), sua presença em espécies forrageiras pode diminuir a aceitabilidade, em função de sua adstringência, que é a sensação causada pela formação de complexos entre os taninos e as glicoproteínas salivares, o que pode aumentar a salivação e diminuir a aceitabilidade do alimento (Reed, 1995). Quanto menor a aceitabilidade, menor a ingestão de alimento $e$, por conseqüência, $a$ produtividade animal. Em vista desses fatores, objetivou-se com a presente pesquisa, determinar a característica físico-química e bioquímica do farelo de palma forrageira redonda (Opuntia fícus), utilizado na alimentação de ruminantes.

\section{Material e Métodos}

O presente estudo foi desenvolvido no Núcleo de Estudos em Ciência de Alimentos - NECAL do Departamento de Estudos Básicos e Instrumentais e no Laboratório de Nutrição Animal do Departamento de Tecnologia Rural e Animal ambos da Universidade Estadual do Sudoeste da Bahia, Campus de Itapetinga.

As raquetes de palma forrageira (Opuntia fícus) foram coletadas durante os meses de abril a junho do ano de 2009, na cidade de Jequié na região de Pedra do Cavalo, Sudoeste do Estado da Bahia, cujas coordenadas são: latitude $13^{\circ} 51^{\prime} 01^{\prime \prime}$, longitude $40^{\circ} 05^{\prime} 01^{\prime \prime}$ e altitude 215 metros com clima semi-árido e 
SILVA, V.L. et al. Caracterização físico-química e bioquímica do farelo de palma forrageira redonda (Opuntia ficus) utilizado na alimentação de ruminantes. PUBVET, Londrina, V. 5, N. 2, Ed. 149, Art. 1002, 2011.

temperatura média anual de $24^{\circ} \mathrm{C}$. As amostras coletadas são procedentes da palma gigante que são plantas de porte médio e caule muito ramificado lateralmente. Suas raquetes apresentaram $1,8 \mathrm{~kg}$ de peso médio, possuindo aproximadamente $40 \mathrm{~cm}$ de comprimento e com forma arredondada e ovóide.

As raquetes in natura foram conduzidas para o setor de Bovinocultura da Universidade Estadual do Sudoeste da Bahia em Itapetinga-BA. Para obtenção do farelo, as amostras foram fatiadas em pequenos pedaços com espessuras de aproximadamente dois centímetros com auxilio de facões e colocadas sobre plástico opaco de cor preta e expostas ao sol para desidratação, onde a cada hora era feita a revirada para melhor incidência da luminosidade natural, até que o seu teor de umidade fosse inferior a $15 \%$. Após este processo, o material desidratado foi triturado em moinho de grãos Nogueira modelo DPM-2 com 3700 rotações por minuto, com peneira de $1 \mathrm{~mm}$ de crivo e armazenadas em frascos de polietileno até o momento das análises.

\section{CARACTERIZAÇÃO FÍSICO-QUÍMICA}

As amostras obtidas foram avaliadas quanto aos teores de matéria seca $(M S)$, matéria mineral $(M M)$, proteína bruta (PB) e extrato etéreo (EE), segundo as metodologias descritas por Silva \& Queiroz (2002), fibra em detergente neutro (FDN) e fibra em detergente ácido (FDA), segundo metodologia de Van Soest et al. (1994) e carboidratos não-fibrosos (CNF), que foi determinado segundo a fórmula: $C N F=100-($ FDN + PB $+E E+C I N Z A S)$, preconizada por Mertens (1997). 
SILVA, V.L. et al. Caracterização físico-química e bioquímica do farelo de palma forrageira redonda (Opuntia ficus) utilizado na alimentação de ruminantes. PUBVET, Londrina, V. 5, N. 2, Ed. 149, Art. 1002, 2011.

\section{ANÁLISES BIOQUÍMICAS}

\section{Compostos fenólicos totais}

Para determinação dos teores foi adotado procedimento proposto por Wettasinghe \& Shahidi (1999), utilizando o reagente de Folin-Ciocauteau.

Foram homogeneizados em tubos de ensaios $0,5 \mathrm{~mL}$ do reagente de FolinCiocauteu, 0,5 mL de extrato e $1,0 \mathrm{~mL}$ de solução saturada de bicarbonato de sódio $\left(\mathrm{NaHCO}_{3}\right)$. O volume da mistura foi ajustado para $10 \mathrm{~mL}$ pela adição de 8 $\mathrm{mL}$ de água destilada e submetidos a agitação vigorosa em agitador de tubos da Marca Quimis Modelo Q-220B2. A mistura foi mantida em repouso à temperatura ambiente $\left(28 \pm 2^{\circ} \mathrm{C}\right)$ por 25 minutos e após este tempo, foi centrifugado a 3600 x g por 5 minutos. A amostra em branco foi constituída de $0,5 \mathrm{~mL}$ do reagente de Folin-Ciocauteu, $0,5 \mathrm{~mL}$ do solvente correspondente, $1 \mathrm{~mL}$ de solução saturada de $\mathrm{NaHCO}_{3}$ e $8 \mathrm{~mL}$ de água destilada. O teor de compostos fenólicos totais foi determinado a 773 nm em espectrofotômetro da Marca Shimadzu, Modelo UV Mini 1240. Para obtenção das curvas analíticas lineares utilizou-se uma solução estoque na concentração de $1 \mathrm{mg} \cdot \mathrm{mL}^{-1}$ e posterior diluição sequencial, variando sua concentração de 0,3 até $0,0125 \mathrm{mg}$ de equivalente de catequina. $\mathrm{mL}^{-1}$. O total de compostos fenólicos nos extratos obtidos foram expressos na tabela 2, em $\mathrm{mg}$ equivalente de catequina. $100 \mathrm{~g}^{-1}$.

\section{Taninos condensados}

Para determinação foi utilizado o método da Vanilina clorídrica, sendo adotado o procedimento proposto por Tiitto-Julkunem (1985).

Foram homogeneizados $0,5 \mathrm{~g}$ de amostra em $30 \mathrm{~mL}$ de solução aquosa de acetona $80 \%\left(v \cdot v^{-1}\right)$, sob agitação constante em agitador magnético, Marca 
SILVA, V.L. et al. Caracterização físico-química e bioquímica do farelo de palma forrageira redonda (Opuntia ficus) utilizado na alimentação de ruminantes. PUBVET, Londrina, V. 5, N. 2, Ed. 149, Art. 1002, 2011.

Fisaton Modelo 752 por 20 minutos à temperatura ambiente ( $\left.28 \pm 2^{\circ} \mathrm{C}\right)$. A mistura foi filtrada e o resíduo ressuspenso em $30 \mathrm{~mL}$ da solução aquosa de acetona $80 \%\left(80: 20\right.$, acetona PA: água, $\left.v \cdot v^{-1}\right)$. Este procedimento foi repetido por duas vezes. Os extratos resultantes foram combinados e o volume final ajustado para $100 \mathrm{~mL}$ com o mesmo solvente. Em um tubo de ensaio previamente revestido com papel alumínio, foram transferidos $0,5 \mathrm{~mL}$ do extrato obtido, $3 \mathrm{~mL}$ da solução metanólica vanilina (4\%, $\mathrm{m} \cdot \mathrm{v}^{-1}$ ). A mistura foi homogeneizada vigorosamente em agitador de tubos. Posteriormente foram adicionados $1,5 \mathrm{~mL}$ de $\mathrm{HCl}$ concentrado, e novamente agitado, sendo mantidos à temperatura ambiente $\left(28 \pm 2{ }^{\circ} \mathrm{C}\right)$ por 20 minutos. As absorbâncias foram medidas em espectrofotômetro Shimadzu UV mine 1240 a 500 nm. Para obtenção das curvas analíticas lineares utilizou-se uma solução estoque na concentração de $25 \mathrm{mg} \cdot \mathrm{mL}^{-1}$ e posterior diluição sequencial variando sua concentração de 1,0 até $3,0 \mathrm{mg}$ de equivalente de catequina $\mathrm{mL}^{-1}$. Os resultados foram expressos na tabela $2 \mathrm{em} \mathrm{mg}$ de catequina. $100 \mathrm{~g}^{-1}$.

As determinações dos teores de compostos fenólicos totais e taninos condensados foram efetuados em triplicata, e os resultados foram apresentados como média \pm desvio padrão (DP), sendo os cálculos realizados no software Excel.

\section{Resultados e Discussão}

A composição físico-química do farelo da palma é variável de acordo com a espécie, idade dos artículos e época do ano (Ferreira, 2005). Os resultados obtidos na caracterização físico-química do farelo de palma forrageira redonda (Opuntia fícus) estão apresentados na tabela 1. 
SILVA, V.L. et al. Caracterização físico-química e bioquímica do farelo de palma forrageira redonda (Opuntia ficus) utilizado na alimentação de ruminantes. PUBVET, Londrina, V. 5, N. 2, Ed. 149, Art. 1002, 2011.

Tabela 1 - Caracterização físico-química do farelo da palma forrageira redonda (Opuntia fícus)

\begin{tabular}{|c|c|c|c|c|c|c|c|}
\hline \multirow{2}{*}{ Amostra } & \multicolumn{7}{|c|}{ Determinação } \\
\hline & $\mathbf{M} \mathbf{S}^{*}$ & $\mathbf{M} \mathbf{M}^{* *}$ & $\mathbf{P B}^{* *}$ & $\mathbf{E E}^{* *}$ & $\mathbf{F D N} \mathbf{N}^{* *}$ & $\mathbf{F D A}^{* *}$ & $\mathbf{C N F}^{* *}$ \\
\hline Opuntia fícus & 10,1 & 15,68 & 5,1 & 0,96 & 28,56 & 22,02 & 49,7 \\
\hline \multicolumn{8}{|l|}{${ }^{*} \%$} \\
\hline \multicolumn{8}{|l|}{${ }^{* *} \%$ na Matéria Seca } \\
\hline \multicolumn{8}{|c|}{$\begin{array}{l}\text { MS = Matéria Seca, MM = Matéria Mineral, PB = Proteína Bruta, EE = Extrato Etéreo, FDN = Fibra } \\
\text { em Detergente Neutro, FDA = Fibra em Detergente Ácido e CNF = Carboidratos Não-Fibrosos }\end{array}$} \\
\hline
\end{tabular}

O valor nutricional e a qualidade dos alimentos são determinados por complexa interação entre os nutrientes ingeridos e a ação dos microrganismos do trato digestivo, nos processos de digestão, absorção, transporte e utilização de metabólitos, além da própria condição fisiológica do animal (Martins et al., 2000).

Independente do gênero, a palma apresenta baixos teores de matéria seca, proteína bruta, fibra em detergente neutro e fibra em detergente ácido.

Os resultados obtidos neste estudo corroboram com Santos (1989) e Ferreira et al. (2005) que foram em torno de $10 \%$ e $5 \%$ para matéria seca e proteína bruta, respectivamente. Segundo Magalhães et al. (2004), em razão do baixo teor de matéria seca da palma forrageira, dietas formuladas com altos percentuais de palma normalmente possuem alto teor de umidade, característica favorável em regiões de baixa pluviosidade em determinadas estações do ano. 0 conteúdo protéico da palma forrageira é considerado baixo, uma vez que para o crescimento e desenvolvimento de microrganismos ruminais responsáveis pela degradação dos nutrientes oriundos da fração fibrosa da forragem, a dieta do animal deve conter níveis em torno de $6 \%$ a $7 \%$ de proteína bruta (Reis et al., 2004). 
SILVA, V.L. et al. Caracterização físico-química e bioquímica do farelo de palma forrageira redonda (Opuntia ficus) utilizado na alimentação de ruminantes. PUBVET, Londrina, V. 5, N. 2, Ed. 149, Art. 1002, 2011.

Normalmente dietas compostas com palma apresentam elevado teor de matéria mineral devido à alta concentração de macroelementos minerais que a mesma contém (Melo et al., 2003).

Mattos et al. (2000) e Santos et al. (2006) encontraram aproximadamente $26 \%$ de fibra em detergente neutro e $22 \%$ de fibra em detergente ácido, de acordo aos apresentados neste estudo que foram respectivamente de $28,56 \%$ e $22,02 \%$. Assim, recomenda-se a sua associação a outros volumosos visando corrigir os baixos teores de fibra em detergente neutro, evitando distúrbios metabólicos, como a diminuição da ruminação e redução nos teores de gordura no leite (Sosa et al., 2005).

A palma destaca-se com 49,7 \% de CNF, valor superior aos apresentados pela CQBAL 3.0 (2009) para o farelo de trigo 31,24 \% e o sorgo em grão 25,14 \%. Valores consideráveis de carboidratos não fibrosos (CNF) favorecem o aumento do consumo de alimentos pelos animais, uma vez que estes são rapidamente fermentados no rúmen, melhorando o aporte de energia.

Recentemente, o estudo de metabólitos secundários tem sido enfatizado para dieta de ruminantes, principalmente relativos a presença de fatores antinutricionais, a exemplo teores de taninos. Neste grupo de metabólitos estão incluídos os compostos fenólicos e seus derivados, como fenóis simples, ácidos fenólicos (derivados de ácidos benzóico e cinâmico), cumarinas, flavonóides, estilbenos, taninos condensados e hidrolisáveis, lignanas e ligninas (Nozella, 2001).

$\mathrm{Na}$ análise feita com o farelo da palma forrageira redonda (Opuntia fícus), foram encontrados os valores que estão apresentados na tabela 2 dos teores de fenólicos totais e taninos condensados pelo método da vanilina. 
SILVA, V.L. et al. Caracterização físico-química e bioquímica do farelo de palma forrageira redonda (Opuntia ficus) utilizado na alimentação de ruminantes. PUBVET, Londrina, V. 5, N. 2, Ed. 149, Art. 1002, 2011.

Tabela 2 - Teores de compostos fenólicos totais e taninos condensados expressos em $\mathrm{mg} \cdot 100 \mathrm{~g}^{-1}$ pelo método da vanilina do farelo da palma forrageira redonda (Opuntia fícus)

\begin{tabular}{ccc}
\hline Amostra & Fenólicos totais & Taninos condensados \\
\hline Opuntia fícus & $168 \pm 0,007024$ & $119,71 \pm 0,004359$
\end{tabular}

Os dados estão apresentados por média de amostras analisadas em triplicata mais desvio-padrão

Foi evidenciado baixos teores desses compostos bioativos na espécie de palma forrageira, que apresentou uma média de 168 e $119,71 \mathrm{mg} / 100 \mathrm{~g}^{-1} \mathrm{de}$ catequina, ou 0,17 e 0,12 quando expressados em \% da matéria seca, respectivamente para fenólicos totais e taninos condensados.

Os valores de taninos condensados encontrados no presente trabalho estam abaixo dos citados como necessários para a promoção de efeitos benéficos (como redução do timpanismo espumoso e aumento de proteína não degradada no rumem que chega ao intestino) que segundo Otero \& Hidalgo (2004) oscila entre 2-4\%. Estão também abaixo do teor considerado prejudicial para a saúde dos animais que em relato de Cruz et al., (2007) teriam que ser superiores a 5\%. Frutos et al., (2002) definiram como quantidade necessária para ocasionar efeito depressivo sobre o consumo voluntário e redução na eficiência do processo digestivo e produtividade animal a ingestão de $6 \%$ a $12 \%$ da matéria seca (MS). O fornecimento de taninos condensados na concentração de $3 \%$ a $4 \%$ da MS aumentou a absorção intestinal de aminoácidos essenciais, sem afetar o consumo (Barry \& McNabb, 1999). Poncet \& Rémond (2002), trabalhando com concentrações médias de $1 \%$ a $2 \%$ na MS, em leguminosas, não detectaram efeito sobre a digestão da proteína.

Em relação aos teores de fenólicos totais, não foram encontrados resultados na literatura, a fim de comparar com os resultados obtidos, e nem, em quais quantidades na forrageira pode causar efeitos negativos aos animais. 
SILVA, V.L. et al. Caracterização físico-química e bioquímica do farelo de palma forrageira redonda (Opuntia ficus) utilizado na alimentação de ruminantes. PUBVET, Londrina, V. 5, N. 2, Ed. 149, Art. 1002, 2011.

O valor encontrado de compostos fenólicos no farelo de palma forrageira redonda (Opuntia fícus) deste trabalho por ser baixo e assim não apresentar problemas aos animais é recomendável para alimentação. É necessário mais pesquisas em relação aos fenólicos totais, pois quando apresentados em maiores proporções podem ter conseqüências não favoráveis.

\section{Conclusões}

Os resultados obtidos revelaram que a palma forrageira redonda (Opuntia fícus) é rica em carboidratos não fibrosos, importante fonte de energia. Entretanto foram observados reduzidos teores de matéria seca e proteína bruta.

Assim sendo, a palma forrageira pode ser considerada como uma boa alternativa complementar para dieta de ruminantes em regiões semi-áridas, devendo esta ser fornecida associada a outras fontes de proteína e de fibra. Apresentando ainda baixos teores de compostos fenólicos totais e taninos condensados, não causando efeitos adversos nos animais, podendo ser utilizada abundantemente.

\section{Agradecimentos}

Agradecemos ao mestrando em Engenharia de Alimentos/Universidade Estadual do Sudoeste da Bahia, Helmo Lima Teixeira, pelo apoio nas análises de compostos fenólicos totais.

\section{Referências Bibliográficas}

BEELEN, P.M.G. Taninos condensados de leguminosas nativas do semi-árido nordestino. 2002. 71f. Tese (Doutorado) - Faculdade de Ciências Agrárias e Veterinárias, Universidade Estadual Paulista, Jaboticabal, SP. 
SILVA, V.L. et al. Caracterização físico-química e bioquímica do farelo de palma forrageira redonda (Opuntia ficus) utilizado na alimentação de ruminantes. PUBVET, Londrina, V. 5, N. 2, Ed. 149, Art. 1002, 2011.

CRUZ, S. E. S. B. S.; BEELEN, P. M. G.; SILVA, D. S. et al. Caracterização dos taninos condensados das espécies maniçoba (Manihot pseudoglazovii), flor-de-seda (Calotropis procera), feijão-bravo (Capparis flexuosa, L) e jureminha (Desmanthus virgatus). Arquivo Brasileiro de Medicina Veterinária e Zootecnia, v. 59, n. 4, p. 1038-1044, 2007.

FERREIRA, M. de A. Palma forrageira na alimentação de bovinos leiteiros. Recife: UFRPE, Imprensa Universitária, p. 68, 2005.

MAGALHÃES, M. C. dos S.; VÉRAS, A. S. C.; FERREIRA, M. de A. et al. Inclusão de cama de frango em dietas à base de palma forrageira (Opuntia fícus-indica Mill) para vacas mestiças em lactação. 1. Consumo e produção. Revista Brasileira de Zootecnia, v.33, n.6, p.18971908, 2004.

MARTINS, A. S.; PRADO, I. N. do; ZEOULA, L. M. et al. Digestibilidade aparente de dietas contendo milho ou casca de mandioca como fonte energética e farelo de algodão ou levedura como fonte protéica em novilhas. Revista Brasileira de Zootecnia, v.29, n.1, p.269-277, 2000.

MATTOS, L. M. E. de; FERREIRA, M. de A.; SANTOS, D. C. et al. Associação da palma forrageira (Opuntia fícus indica Mill) com diferentes fontes de fibra na alimentação de vacas $5 / 8$ Holandês-Zebu em lactação. Revista Brasileira de Zootecnia, v.29, n.6, p.2128-2134, 2000.

MELO, A. A. S. de; FERREIRA, M. de A.; VÉRAS, A. S. C. et al. Substituição parcial do farelo de soja por uréia e palma forrageira (Opuntia fícus indica Mill) em dietas para vacas em lactação.

I. Desempenho. Revista Brasileira de Zootecnia, v.32, n.3, p.727-736, 2003.

MERTENS, D.R. Creating a system for meeting the fiber requirements of dairy cows. Journal of Dairy Science, v.80, n.7, p.1463-1481, 1997.

NOZELLA, E. F. Determinação de taninos em plantas com potencial forrageiro para ruminantes. 2001. 58f. Dissertação (mestrado) - Centro de Energia Nuclear na Agricultura da Universidade de São Paulo, Piracicaba, SP.

OTERO, M. J; HIDALGO, L. G. Taninos condensados en especies 227 forrajeras de clima templado: efectos sobre la productividad de rumiantes afectados por parasitosis gastrointestinales (uma revisión). Livestok Research of Rural Developement, v. 16 n.2, 2004.

REED, J.D. Nutritional toxicology of tannins and related polyphenols in forage legumes. Journal of Animal Science, v.73, p.1516- 1528, 1995.

REIS, R. A.; BERTIPAGLIA, L. M. A.; FREITAS, D. et al. Suplementação protéica energética e mineral em sistemas de produção de gado de corte nas águas e nas secas. In.: Pecuária de corte intensiva nos trópicos. $1^{a}$ ed. Piracicaba: FEALQ, 2004, v.1, p. 171- 226.

SANTOS, M.V.F. Composição química, armazenamento e avaliação da palma forrageira (Opuntia ficus indica Mill. e Nopalea cochenillifera Salm-Dyck) na produção de leite, em Pernambuco. 1989. 120p. Dissertação (Mestrado em Nutrição Animal) - Universidade Federal Rural de Pernambuco, Recife, PE. 
SILVA, V.L. et al. Caracterização físico-química e bioquímica do farelo de palma forrageira redonda (Opuntia ficus) utilizado na alimentação de ruminantes. PUBVET, Londrina, V. 5, N. 2, Ed. 149, Art. 1002, 2011.

SILVA, M. R.; SILVA, M. A. A. P. Aspectos nutricionais de fitatos e taninos. Revista de Nutrição, v.12, n.1, p.5-19, 1999.

SILVA, D. J.; QUEIROZ, A. C. de. Análise de Alimentos: métodos químicos e biológicos. 3. ed. Editora UFV: Viçosa-MG, 2002. 235p.

SILVA, C. C. F. da; SANTOS, L. C. Palma forrageira (Opuntia fícus- indica Mill) como alternativa na alimentação de ruminantes. Revista Eletrônica de Veterinária REDVET ®, ISSN 16957504, Vol. VII, no 10, Out. 2006.

Software da Windows - Planilha eletrônica, Microsoft Office Excel. 2007.

SOSA, M.Y.; BRASIL, L.H.de A.; FERREIRA, M. de A, et al. Diferentes formas de fornecimento de dietas a base de palma forrageira e comportamento ingestivo de vacas da raça holandesa em lactação. Acta Scientiarum Animal Science, v. 27, n.2, p. 261-268, 2005.

TIITTO-JULKUNEM, R. Phenolic constituents in the leaves of Northem Willows: methods for the analysis of certain phenolics. Journal of Agricultural of Food Chemistry, v. 33, n. 2, p.213-217, 1985.

VAN SOEST, P.J. Nutritional ecology of the ruminant. 2 ed. Ithaca: Cornell University Press, p. $476,1994$.

WETTASINGHE, M., SHAHIDI, F. Evening Primrose Meal: A Source of Natural Antioxidants and Scavenger of Hydrogen Peroxide and Oxygen-Derived Free Radicals. Journal of Agricultural and Food Chemistry, v. 47, n. 5, p. 1801-1812, 1999. 